\title{
Climatology of the inter-hemispheric field-aligned current system in the equatorial ionosphere as observed by CHAMP
}

\author{
J. Park ${ }^{1}$, H. Lühr ${ }^{1}$, and K. W. Min ${ }^{2}$ \\ ${ }^{1}$ GFZ, German Research Center for Geosciences, Potsdam, Germany \\ ${ }^{2}$ Department of Physics, Korea Advanced Institute of Science and Technology, Daejeon, Korea
}

Received: 9 September 2010 - Revised: 27 December 2010 - Accepted: 3 March 2011 - Published: 24 March 2011

\begin{abstract}
From geomagnetic field observations of CHAMP during 2001-2009 we extracted characteristic signatures of inter-hemispheric field-aligned currents (IHFACs) in the equatorial ionosphere. The results are in general agreement with previous observations. Nighttime IHFACs are negligibly small. Solstitial IHFACs flow from the summer to winter (from winter to summer) hemisphere at dawn (around noon). Duskside IHFACs flow southbound irrespective of season. We have also found some new IHFAC properties, which may have been predicted by theories, but are not yet given observational support. IHFACs clearly exhibit a longitude dependence, which is modulated by the South Atlantic Anomaly, the offset between geographic and magnetic equators, and tidal waves. IHFACs show little dependence on the solar cycle. We provide a comprehensive assessment of the IHFAC modulation by non-migrating tides.
\end{abstract}

Keywords. Ionosphere (Electric fields and currents; Equatorial ionosphere; Ionosphere-atmosphere interactions)

\section{Introduction}

In the dayside ionospheric E-region there exists a current vortex in each hemisphere, which is known as solar-quiet (Sq) current system (e.g., van Sabben, 1964). The currents flow counterclockwise (clockwise) in the Northern (Southern) Hemisphere with the focuses around $30^{\circ}-35^{\circ}$ dip latitudes (e.g., Matsushita and Maeda, 1965). The current intensity exhibits positive correlation with solar activity, and is stronger (weaker) in the summer (winter) hemisphere with the total (north+south) intensity maximizing dur-

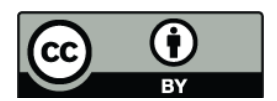

Correspondence to: J. Park (park@gfz-potsdam.de) ing equinoxes (Takeda, 2002). It is generally accepted that the Sq current system originates from the dynamo action of neutral wind (e.g., Chapman and Bartels, 1940; Tarpley, 1970; Fukushima, 1979). The Sq currents have been investigated for decades both theoretically and observationally (e.g., Matsushita and Maeda, 1965; Stening, 1971, 1989; Takeda, 1996; Campbell, 1997; Chulliat et al., 2005; Rastogi, 2006). It has been discussed controversially whether the Sq current system is connected to the Equatorial Electrojet (EEJ). Some papers support their close relationship (e.g., Mayaud, 1967; Hesse, 1982) while others raise questions thereon (e.g., Ogbuehi et al., 1967; Okeke and Onwumechili, 1993; Manoj et al., 2006) (see Okeke, 2006, for detailed discussions).

A north-south asymmetry of the Sq vortices (especially during solstices) is expected to create a potential difference between the hemispheres (e.g., van Sabben, 1966; Fukushima, 1979; Onwumechili, 1997; Tomás et al., 2009), resulting in inter-hemispheric field-aligned currents (IHFACs). Asymmetries in neutral wind and conductivity (e.g., Maeda, 1974; Takeda et al., 2003) are known to contribute to the IHFAC generation. The existence of IHFAC was evidenced experimentally for the first time by Magsat observations (Olsen, 1997). Yamashita and Iyemori (2002) reported an IHFAC climatology using data from the Ørsted satellite and world-wide ground geomagnetic observatories. They confirmed that (1) IHFACs flow from summer to winter (from winter to summer) in the dawn (noondusk) sector, which was predicted by theoretical works (e.g., Takeda, 1982; Fukushima, 1994), and (2) the IHFAC direction change does not occur exactly at equinox epochs and the IHFAC intensity does not peak at solstices.

Though the work of Yamashita and Iyemori (2002) was the first global climatology of IHFACs, there still remains room for further studies. First, as the local time (LT) of the

Published by Copernicus Publications on behalf of the European Geosciences Union. 

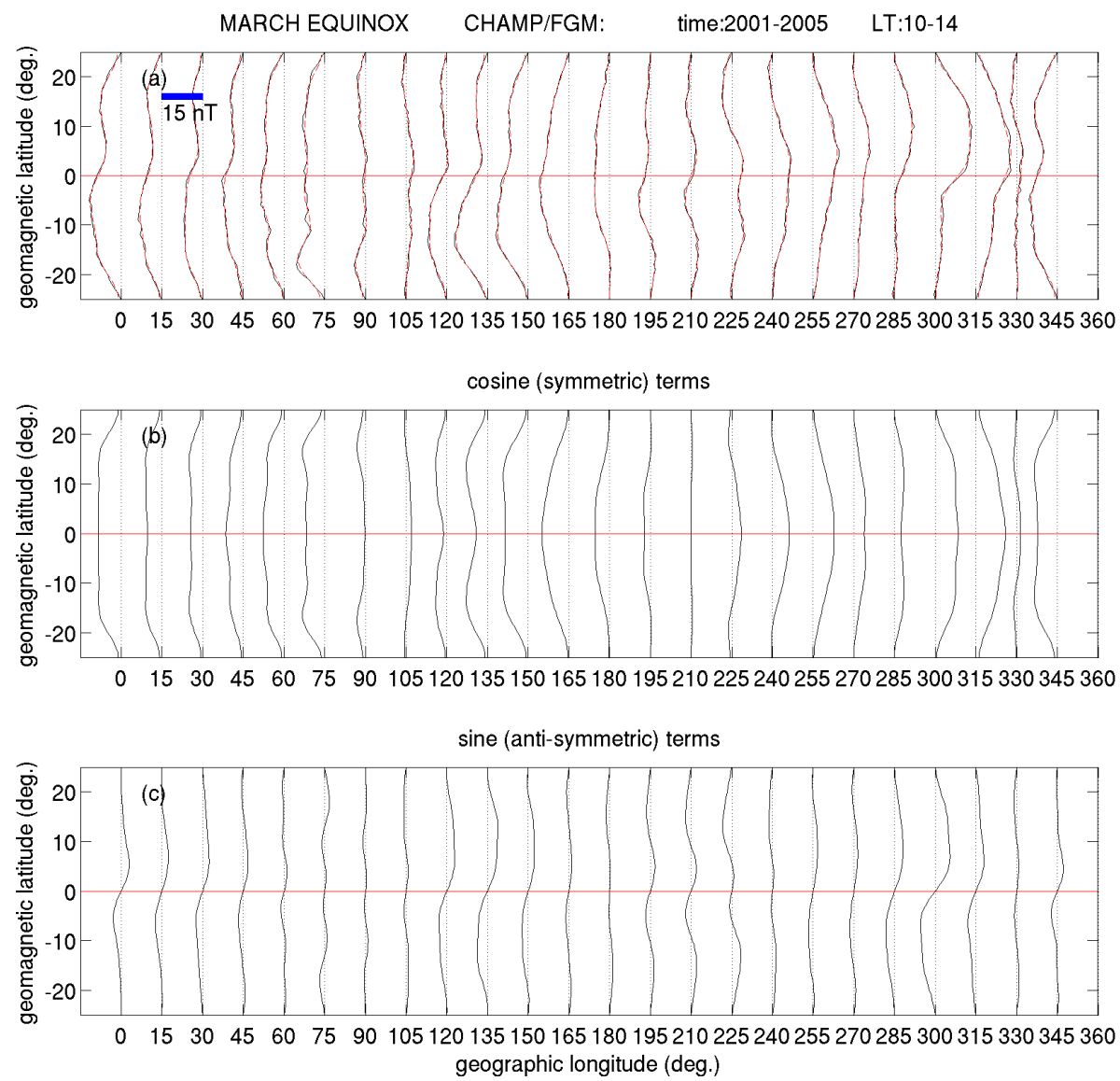

Fig. 1. Examples of average magnetic field deflection at low latitude; (a) linearly detrended latitudinal profile of the zonal residual field. (b) Symmetric component with respect to the dip equator. IHFAC can be estimated from this component. (c) Anti-symmetric component with respect to the dip equator. The standard error of the mean is below $0.6 \mathrm{nT}$ for each curve in a longitude bin due to the large number of observations (1600-4900 per cell).

Ørsted orbit changes only $0.9 \mathrm{~min} /$ day, it takes longer than 2 years for all LT sectors to be probed. Yamashita and Iyemori (2002), using Ørsted observations from April 1999 to October 2001, could not deduce the full seasonal-LT variations of IHFAC. In their Fig. 5 seasonal and LT variations are not sufficiently separated, and they cannot tell which part of the IHFAC variations comes from the effect of LT or season. The seasonal/LT variation of IHFAC reported in Yamashita and Iyemori (2002) was deduced instead from a world-wide array of magnetic observatories. However, the magnetic deflections observed on ground cannot separate uniquely the effect of Sq currents from that of IHFACs, which may degrade the quality of IHFAC estimation (Yamashita and Iyemori, 2002). Actually, their ground-based results sometimes show differences from Ørsted observations; e.g., the nighttime IHFAC amplitudes derived by ground-based observations were finite while those derived by Ørsted were negligible. This is the second point worth testing.

In this paper we present a comprehensive IHFAC climatology, which can clarify the open points mentioned above, based on 9 years of in-situ magnetic field observations by the CHAMP (Challenging Mini-satellite Payload) spacecraft. The relevant instruments and data processing approaches are described in Sect. 2, and the IHFAC climatology is presented in Sect. 3. Results are discussed in Sect. 4 and summarized in Sect. 5.

\section{Instrumentation and data processing}

CHAMP was launched in July 2000 into a near-polar circular orbit. Its altitude was around $450 \mathrm{~km}$ right after launch and has decayed to below $250 \mathrm{~km}$ as of September 2010. Due to the orbit precession it takes about 131 days for CHAMP to sweep all LTs. A Flux-Gate Magnetometer (FGM) and an Overhauser Scalar Magnetomer (OVM) provide geomagnetic field data at a nominal rate of $1 \mathrm{~s}$. For extracting $\mathrm{IH}-$ FAC components from these data we adopt a method similar to that of Yamashita and Iyemori (2002). First, we remove contributions from the Earth's core-, lithospheric and magnetospheric currents (which we call "mean field" hereafter) 

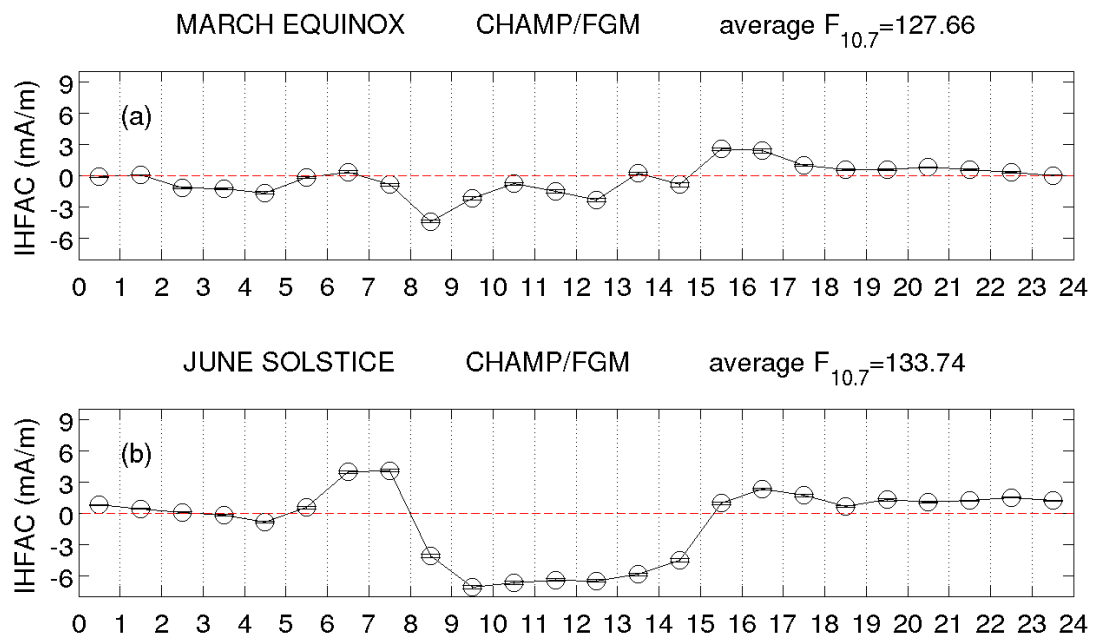

SEPTEMBER EQUINOX CHAMP/FGM average $\mathrm{F}_{10.7}=142.13$
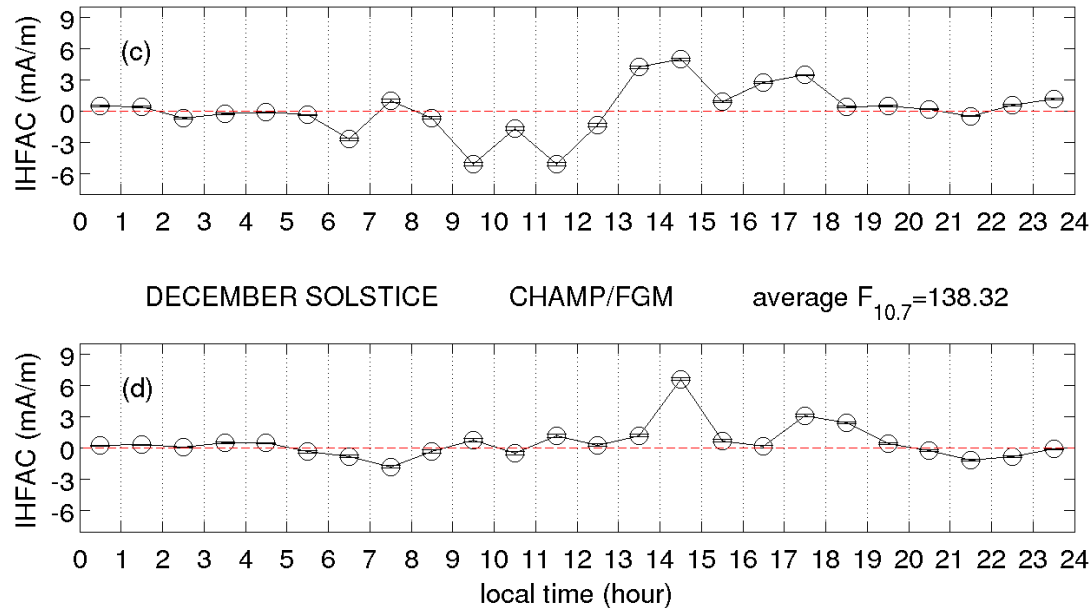

Fig. 2. Local time variation of IHFACs. Each panel corresponds to a season, with the average solar radio flux $\left(F_{10.7}\right)$ given in the headings. Positive values of IHFAC represent current flowing from north to south. The standard error of the mean is below $0.2 \mathrm{~mA} \mathrm{~m}^{-1}$ for each point due to the large number of observations (7600-21 000 per cell).

using the Pomme6 model (http://www.geomag.org/models/ pomme6.html). The residues are called "residual field" hereafter. IHFACs produce magnetic deflections perpendicular to the mean field (zonal/meridional). Here we concentrate on the zonal component perpendicular to the magnetic meridian. Second, the zonal residual fields are binned in cells of $1^{\circ}$ geomagnetic latitude (MLAT) by $30^{\circ}$ in geographic longitude (GLON), separately for each season. There are 24 overlapping GLON bins. Zonal residual field data are rejected if the amplitude is larger than $50 \mathrm{nT}$ or the daily-averaged $\mathrm{Kp}$ index exceeds 4 (Park et al., 2010). The magnetic quasi-dipolar coordinates, as defined by Richmond (1995), are used in this work as reference frame. For LT profiles, on the other hand, the data are binned in 1-h LT cells. Third, each latitude profile of the zonal residual fields is linearly detrended (Fig. 1a) and separated into hemispherically symmetric (Fig. 1b) and anti-symmetric (Fig. 1c) parts by Fourier transform. Details of the procedure are given in Park et al. (2010). The antisymmetric component in Fig. 1c is interpreted as caused by the equatorial F-region wind dynamo as described in Park et al. (2010). The symmetric component in Fig. 1b is related to IHFAC, i.e. the subject of this paper:

$$
J_{\text {IHFAC }}=\frac{1}{\mu_{0}} B_{\text {equator }}^{\text {symm }} \text {, }
$$

where $J_{\text {IHFAC }}$ is the height-integrated sheet current density of IHFAC above the magnetic equator, $\mu_{0}$ is the permeability of free space, and $B_{\text {equator }}^{\text {symm }}$ is the amplitude of the symmetric component of the zonal magnetic residual at the magnetic equator. Note that we only consider readings within $\pm 25^{\circ}$ MLAT (at CHAMP altitude) while Park et al. (2010) used a limit of $\pm 45^{\circ}$ MLAT. $\pm 25^{\circ}$ MLAT at CHAMP altitudes corresponds approximately to field-line foot-print latitudes 

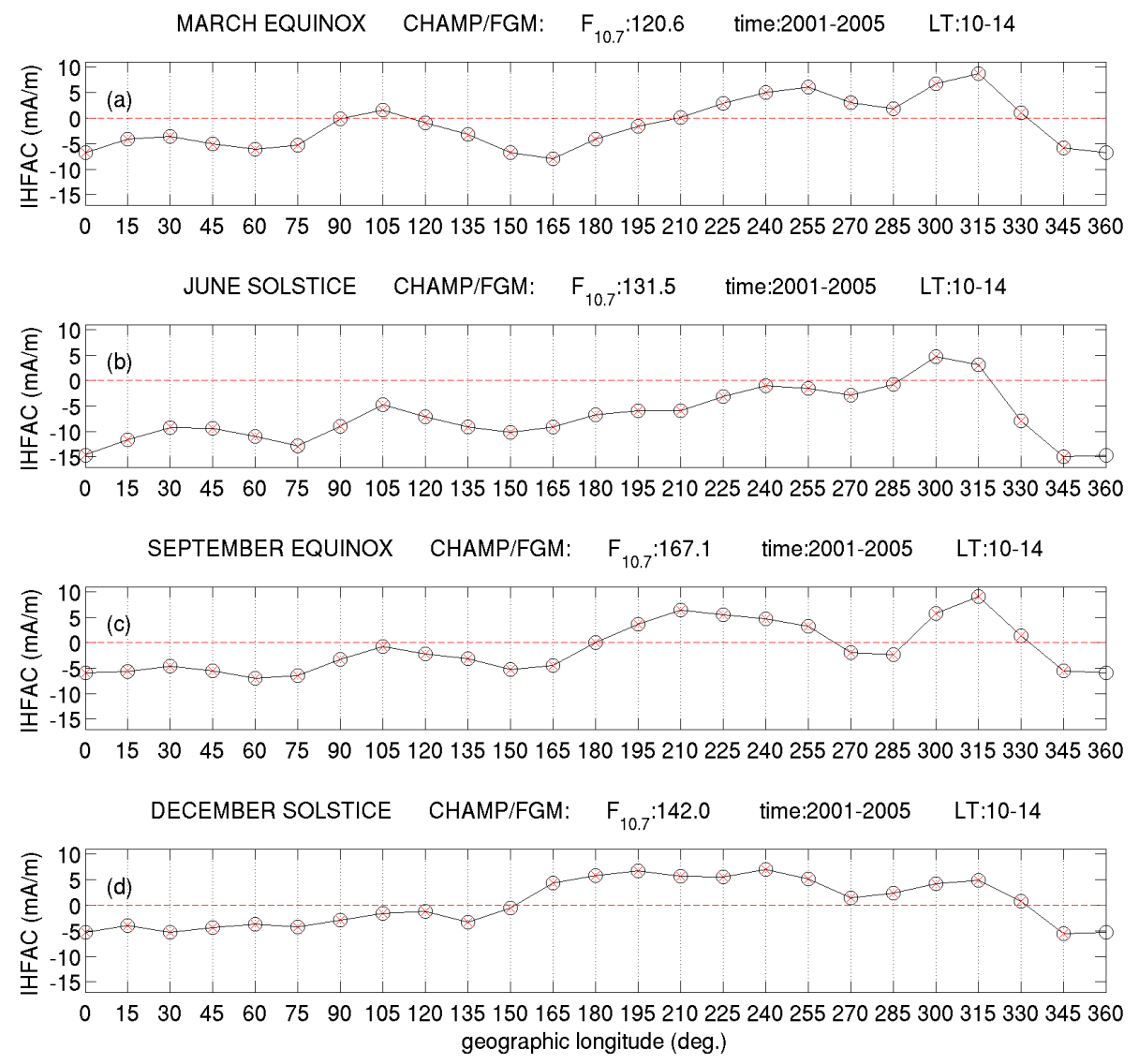

Fig. 3. Longitudinal variation of noontime IHFACs. Each panel corresponds to a season, with the average solar radio flux $\left(F_{10.7}\right)$ given in the headings. The standard error of the mean is below $0.5 \mathrm{~mA} \mathrm{~m}^{-1}$ for each point due to the large number of observations (1600-4900 per cell).

of $\pm 37^{\circ}$ at $110 \mathrm{~km}$ (height of the E-layer), where the foci of Sq vortices are expected (e.g., Matsushita and Maeda, 1965).

\section{Results - climatology of IHFAC}

For the investigations of the IHFAC we utilized CHAMP data of the years 2001-2005 (2005-2009) which comprise high (low) solar activity conditions. In this section we present only results from the earlier (near solar maximum) period in order to compare our findings with previous works, especially those of Yamashita and Iyemori (2002). In the next section, results from both time periods will be described in detail and compared with each other. Figure 2 shows the LT variation of IHFAC. Each panel corresponds to a season, where the average solar radio flux $\left(F_{10.7}\right)$ is given in the headings. The Sq current system is known to respond to changes of seasons with a delay of 1-2 months (Takeda, 2002; Yamashita and Iyemori, 2002): i.e. solstitial conditions appear 1-2 months after the true solstice. Hence, each season in our paper is defined as a three-month period starting from the corresponding equinox/solstice month: e.g., March equinox lasts from March to May. Positive values of IHFAC represent currents flowing from north to south.

First, we can see that IHFAC amplitudes are negligible during nighttime (19:00-05:00 LT), as expected. In the early morning hours (05:00-08:00 LT) IHFACs are southbound (positive) during June solstice while it is weakly northbound (negative) around December solstice. Around noon (10:0015:00 LT) IHFACs are northbound (negative) during June solstice. During December solstice IHFACs are marginally southbound (positive) near noon, and maximize at a later LT sector (14:00-15:00 LT). Near dusk (15:00-19:00 LT), IHFACs during June solstice change their direction from the one at noontime to more southbound (positive). On the other hand, IHFACs during December solstice generally retain the afternoon polarity.

In general, solstitial IHFACs flow from the summer to winter hemisphere during early morning hours $(05: 00-08: 00$ LT) and from winter to summer at daytime (10:00-15:00 LT). Duskside (15:00-19:00 LT) IHFACs are southbound (positive) in all the seasons. That means, it exhibits dawn-like (daytime-like) polarity during June solstice (December solstice). During equinoxes, LT variations of IHFAC show an 

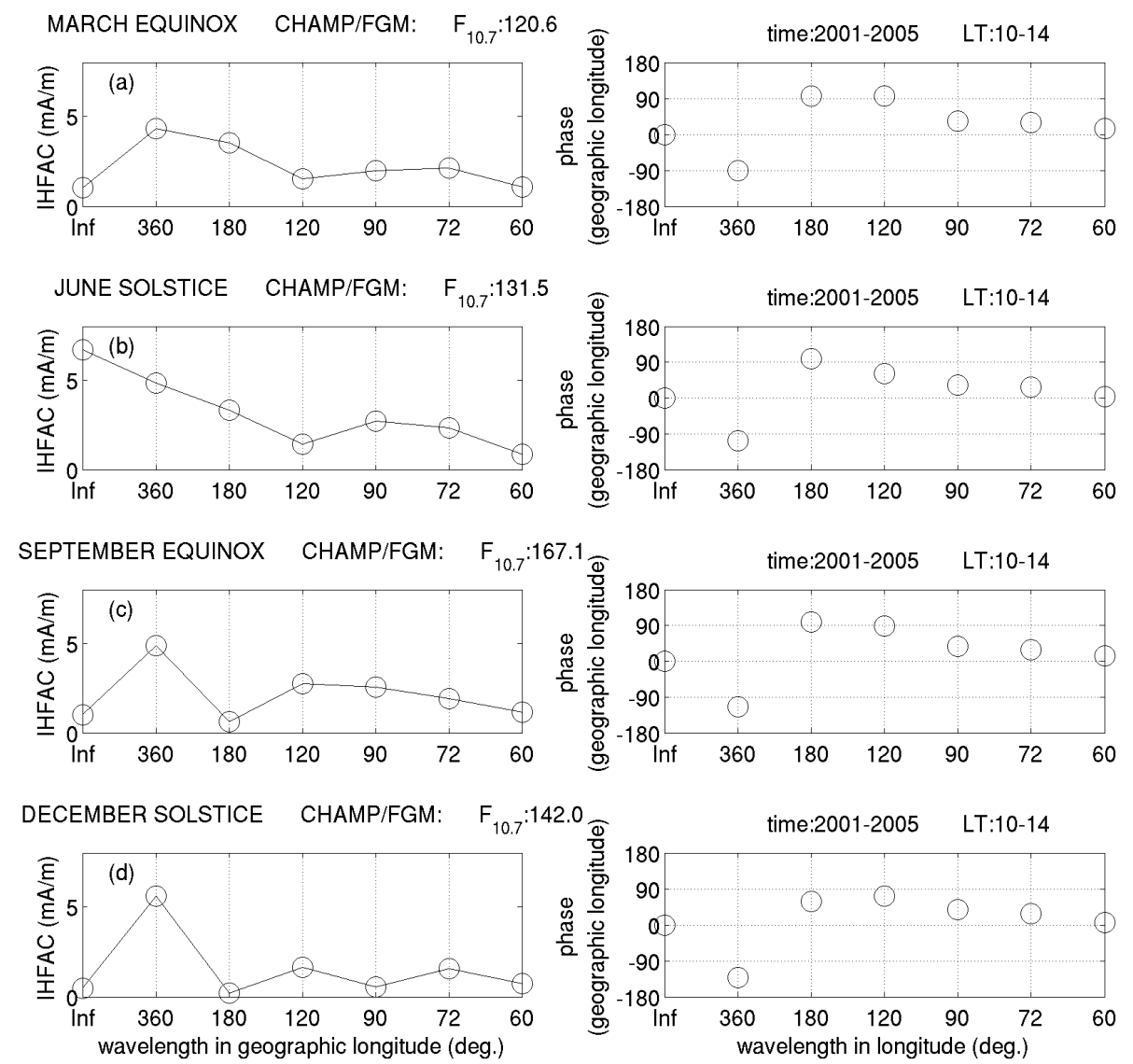

Fig. 4. Amplitude (left column) and phase (right column) spectra of longitudinal variation of IHFACs given in Fig. 3. Each row corresponds to a season.

intermediate behavior between the two solstitial patterns, and the pattern fluctuates around zero.

Figure 3 shows longitudinal variations around noontime (10:00-14:00 LT) of IHFACs for each season. First, average levels of IHFACs are generally negative during June solstice. At equinoxes and December solstice the longitudinal variations are roughly centered around zero current. Second, IHFACs around $300^{\circ} \mathrm{E}$, the longitude of the South Atlantic Anomaly (SAA), show local maxima (more positive values) during all seasons. We can also see, irrespective of season, that IHFACs in the western longitudes $\left(180-360^{\circ} \mathrm{E}\right)$ around noon are more positive (southbound) than those in the eastern longitudes. Third, the longitudinal IHFAC distribution roughly exhibits four peaks during June solstice and equinoxes though the maxima are not at regular spacing. The 4-peak signature vanishes during December solstice.

\section{Discussion}

IHFAC densities, as given in Figs. $2-3$, are generally in the range between -15 and $+15 \mathrm{mAm}^{-1}$. According to Eq. (1) this corresponds to zonal magnetic deflections between -20 and $+20 \mathrm{nT}$. Figure 5 of Yamashita and Iyemori (2002) shows that the amplitudes of IHFAC-associated zonal magnetic deflections are generally within $\pm 20 \mathrm{nT}$, but sometimes exceed $20 \mathrm{nT}$. Their values are in general agreement with our results, but the peak values are slightly higher. Let us assume that a homogeneous sheet current of $6 \mathrm{~mA} \mathrm{~m}^{-1}$, based on Fig. 2b, flows between 09:00 to 14:00 LT $(\sim 8300 \mathrm{~km}-$ wide zonal sector) from one hemisphere to the other. Then the total IHFAC amounts to $\sim 50 \mathrm{kA}$. Model calculations of Maeda (1974) estimated that the integrated daytime IHFAC amounts to several hundred $\mathrm{kA}$, which is significantly larger than our zonally-averaged results based on CHAMP observations. According to Fig. 6 of Takeda (2002), total Sq currents during June solstice are about 200-400 kA. We can see that IHFACs constitute a significant portion (12-25\%) of the Sq current system.

\subsection{Local time variations}

The LT variation of IHFACs, as shown in Fig. 2, is generally consistent with previous works: (1) solstitial IHFACs flow from summer to winter in the morning and from winter to summer during the daytime, and (2) daytime IHFAC 
maximizes later in LT during December solstice than during June solstice (e.g., consistent with Fig. 6 of Yamashita and Iyemori, 2002). However, our duskside (15:00-19:00 LT) IHFACs are inconsistent with the currently-accepted concept (e.g., Fig. 17 of Fukushima, 1994), where duskside IHFACs always exhibit the same polarity as at noon. In our Fig. 2 duskside IHFACs flow southbound irrespective of season. Olsen (1997) showed, using Magsat data near December solstice, that dawnside and duskside IHFACs exhibit opposite directions (dawnside: summer-to-winter and duskside: winter-to-summer). Yamashita and Iyemori (2002), using Ørsted data near December solstice, also showed that duskside IHFACs flow from winter to summer (see their Fig. 5 and Table 4). All these observations are consistent with our Fig. 2 as well as with the concept of Fukushima (1994). To our knowledge, there is no publication of satellite-based observation on duskside IHFAC around June solstice. Using ground observations at the Vassouras station, Brazil (GLAT: $-22.4^{\circ}$, GLON: $316.35^{\circ} \mathrm{E}$ ), Yamashita and Iyemori (2002) presented IHFAC diurnal variations for each solstice (see their Fig. 6a). During December solstice the IHFAC directions show the following diurnal change: (1) from summer to winter before 10:00 LT, (2) from winter to summer after 10:00 LT, with a small decrease around 16:00 LT. This diurnal variation agrees with our Fig. 2 as well as with the concept of Fukushima (1994). During June solstice IHFAC directions show the following diurnal change: (1) from summer to winter before 08:30 LT, (2) from winter to summer between 08:30 LT and 13:00 LT, and (3) from summer to winter after 13:00 LT. This diurnal variation does not agree with the concept of Fukushima (1994), but with our Fig. 2b. Yamashita and Iyemori (2002) also conducted similar investigation using 17 ground observatories. The results were roughly consistent with those at the Vassouras station (and with our results). Just the observations in the Northern Hemisphere exhibited differences from those at the Vassouras station during October-March. Yamashita and Iyemori (2002) refrained from drawing a clear conclusion on duskdise IHFACs and left the subject open for future work. Our results generally support their observations, including those which are inconsistent with the currently-accepted concept of duskside IHFAC (e.g., Fig. 17 of Fukushima, 1994). More theoretical work is needed to accommodate these observations into the context of global current systems.

\subsection{Longitudinal structures of IHFAC}

Now we discuss the longitudinal IHFAC variation around noontime as shown in Fig. 3. This has never been investigated by previous works. A spectral analysis was performed separately for each season. Figure 4 gives amplitude (left column) and phase (right column) spectra of the signals in Fig. 3. The horizontal axis represents the wavelength in degree GLON: "Inf" corresponds to the longitudinally averaged IHFAC amplitude, "360" to wavenumber-1 signature, and so on. We can see that the average IHFAC magnitude is smaller (larger) during December solstice (June solstice). It seems that the selected LT sector (10:00-14:00 LT) has lead to this solstitial asymmetry. Figure 2 shows that the IHFAC amplitude during December solstice peaks later (after 14:00 LT) than during June solstice. We have, nevertheless, chosen this local time interval (10:00-14:00 LT) because the longitudinal structures (as will be shown later in Figs. 5 and 6) are clearest in that LT sector. During all seasons the wavenumber- 1 signature has its crest around $220-270^{\circ} \mathrm{E}$, indicating that IHFACs are more southbound (northbound) in the western (eastern) longitudes. Our results show that IHFACs around noon are more southbound (or less northbound) in the longitude range where the magnetic equator is located to the south of the geographic equator. According to Fig. 3b of Fukushima (1979), if the magnetic equator is located to the south of the geographic equator, a larger amplitude of winter-to-summer IHFAC is expected during December (southward/positive IHFAC) than during June solstice (northward/negative IHFAC). The opposite characteristics is observed at eastern longitudes where the magnetic equator is located to the north of the geographic equator: larger amplitude of winter-to-summer IHFACs are expected during June (northward/negative IHFAC) than during December solstice (southward/positive IHFAC). For a specific season these features can bias IHFACs to more southbound (positive) values in the western longitudes.

Moreover, the wavenumber-1 structure can be enhanced by the existence of the SAA. As seen in Fig. 3, the noontime IHFACs around the SAA are systematically more positive (southbound) irrespective of seasons. Note that the IHFAC around noon flows from winter (weaker Sq current) to summer (stronger Sq current). This suggests that the Sq system is enhanced in the SAA region. It may be, first, because the ionospheric dynamo currents get stronger as the ambient magnetic field is weak (Takeda, 1996). It was suggested that a weak B-field (lower gyro-frequency) shifts the effective dynamo altitude upwards where the plasma density and wind speed are higher (Takeda, 1996). Hence, Sq currents near the SAA are expected to be stronger (summer-like condition) than in the conjugate Northern Hemisphere (winter-like condition). Second, the E-region conductivity is enhanced in the SAA due to particle precipitation (e.g., Abdu et al., 2005). This also contributes to an Sq current enhancement (summerlike condition) around the SAA, which in turn causes a positive (southbound) IHFAC in the noontime.

\subsection{Tidal wave signatures in IHFAC}

Longitudinal variations with wavenumber 4 , as evident in Fig. 3, are quite common in ionospheric quantities (e.g., Lühr et al., 2008; England et al., 2010; Park et al., 2010, and references therein). Eastward-propagating non-migrating diurnal tides with wavenumber 3 (DE3) are a major source for wave4 signatures in the ionospheric E-layer (e.g., Hagan et al., 
2007). In addition, DE2 tides can make significant contributions to wave-3 signatures (Pedatella et al., 2008). In Fig. 3 we can identify 4 peaks during equinoxes and June solstice, though the inter-peak distances are slightly uneven. Wave-4 component, in concert with adjacent harmonics, can produce the 4-peak structure with uneven inter-peak distances. In the amplitude spectra of Fig. 4 we can see that the wave- 4 signature is most prominent during June solstice (note that we have defined this season as June-August). The wave- 4 component is still noticeable during equinoxes, but adjacent harmonics also exhibit significant contribution. The wave-4 harmonic is negligible during December solstice (DecemberFebruary). So far the tidal studies are mainly focused on equatorial latitudes. Oberheide et al. (2009) have shown that DE3 tidal zonal winds maximize at the equator in the E-layer $(100-110 \mathrm{~km})$. Most favorable season are the months July to September. Around December solstice DE3 practically disappears. DE2 on the other hand exhibits sizable amplitudes during December (Pedatella et al., 2008). For our investigations the tidal signatures at low-to-middle latitudes are important. Unfortunately, all publications on tidal signatures in ionospheric quantities describe equatorial phenomena (e.g., Lühr et al., 2007, 2008; Park et al., 2010; England et al., 2010, and references therein).

In spite of our lack of understanding some features of tidal signature in IHFAC should be stated here. The described seasonal variation is in general agreement with the amplitudes in our Figs. 3-4. In the phase spectra the first crest of the wave number-4 structure appears at longitudes around $35^{\circ} \mathrm{E}$ during 10:00-14:00 LT at all seasons. In particular the coherent phase value of the wave-4 signal is a supporting fact for a tidal origin. For better assessment of the tidal influence on IHFAC more information is needed about the modulation of winds in the E-layer by DE2 and DE3 tides at low-to-middle latitudes.

Zhang et al. (2010) showed that the DE3 temperature wave at $110 \mathrm{~km}$ altitude exhibits larger amplitudes in the Southern than Northern Hemisphere (see their Fig. 16). We can confirm this bias even for the zonal wind in Fig. 2a of Oberheide and Forbes (2008). As DE3 winds modulate the daytime E-region dynamo at wave-4 wavelengths, its southern bias can enhance Sq currents at the southern wave- 4 crests. Note again that the noontime IHFACs flow from weaker to stronger Sq current vortices. According to our observations the tidal forcing intensifies the southern $\mathrm{Sq}$ system around noon at longitudes of $35^{\circ}, 125^{\circ}, 215^{\circ}$, and $305^{\circ} \mathrm{E}$, where IHFACs are more southbound (more positive) or less northbound (less negative) than the longitudinal averages (Fig. 3ac). At longitudes in between the southern Sq system should be weakened, so that IHFACs are less southbound (less positive) or more northbound (more negative) than the longitudinal averages. This suggestion has to be tested, and more simulation work is needed.
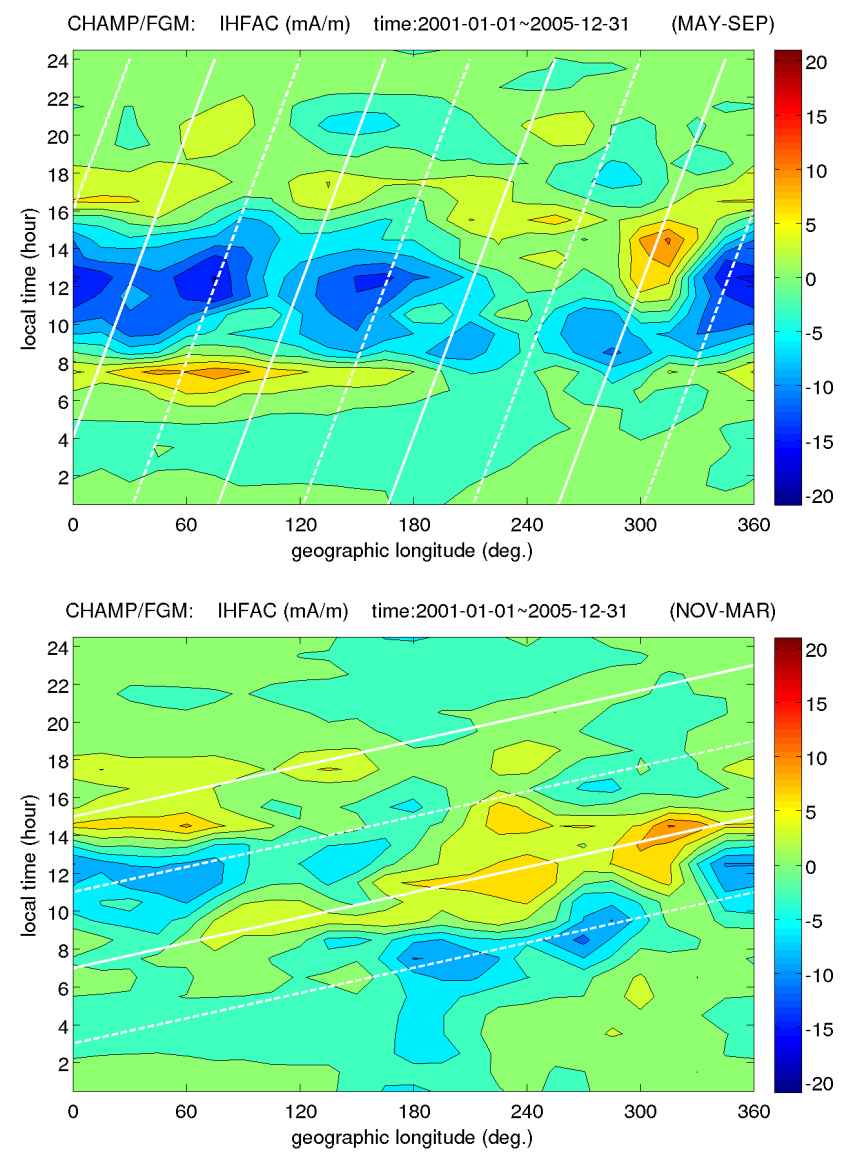

Fig. 5. IHFAC amplitudes are shown as a function of LT and GLON. The upper (lower) panel corresponds to May-September and November-March in 2001-2005, respectively. The contour lines are drawn for each $3 \mathrm{~mA} \mathrm{~m}^{-1}$ interval.

\subsection{Comprehensive view of IHFAC features}

In the previous sections we have looked at IHFAC variations in LT and GLON distribution individually by keeping one of the parameters constant. This was done primarily in order to get results in a format comparable to previous studies. As we have shown that our results are in general agreement with earlier analyses, we want to go a step further. The large amount of CHAMP magnetic field data allows a more comprehensive view of the IHFAC characteristics. Our aim in this subsection is to look simultaneously at LT and GLON variations. For this purpose the CHAMP data set was separated into two seasonal parts covering the months May-September (northern summer condition) and November-March (northern winter condition).

In Fig. 5 the IHFAC amplitude distribution is shown in an LT versus GLON frame for both seasonal parts. Here we have focused on the solar maximum years 2001-2005. When looking at the top frame (May-September) we find in the longitude sector $0-180^{\circ} \mathrm{E}$ the classical picture of IHFAC distribution, southward currents during morning and evening 

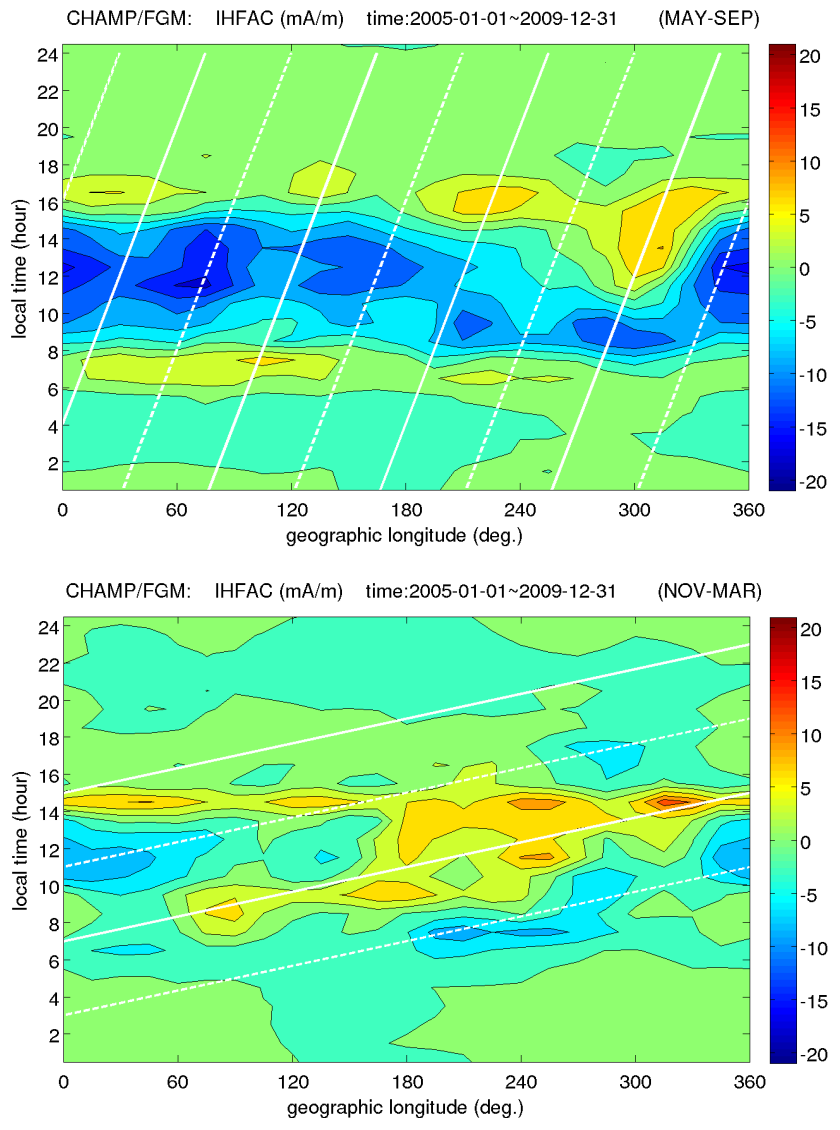

Fig. 6. The same as Fig. 5, but for 2005-2009.

hours and major northward currents during daytime. At locations to the east of $180^{\circ} \mathrm{E}$ the whole current system shifts to earlier LTs causing the disappearance of the southbound morning currents and an intensification of the southbound afternoon IHFACs. During the months November-March the IHFAC distribution is quite different (see Fig. 5, lower frame). In the longitude sector $0-180^{\circ} \mathrm{E}$ we find northward IHFAC near noon and southbound currents in the afternoon (after 14:00 LT). The peaks of current density shift gradually to later LTs for locations further east. Around $180^{\circ} \mathrm{E}$ there is an abrupt switch in current configuration: both northbound and southbound IHFACs appear $8 \mathrm{~h}$ earlier in LT. Further east of $180^{\circ} \mathrm{E}$ current structures shift again to later LTs. Irrespective of season, noontime IHFACs are more southward (positive) in the western than eastern longitudes, consistent with Fig. 3b of Fukushima (1979). An outstanding feature of strong southward IHFAC appears at longitudes close to $300^{\circ} \mathrm{E}$ near noon. It marks the intense IHFACs flowing into the Sq system forming over the SAA. Processes possibly responsible for this phenomenon have already been discussed in Sect. 4.2.

White lines are overplotted onto the IHFAC features, which represent wave fronts of non-migrating tides. In the top frame (May-September) we plot crests (full lines) and valleys (dashed lines) of DE3 tides. Longitudes of wave maxima have been chosen based on the phase value of wave4 from Fig. 4. It is convincing to see that the lines connect the local minima and maxima of IHFAC density between 09:00 and 17:00 LT. The solid (dashed) lines correspond to more southward/positive (northward/negative) IHFAC at a given LT. According to the tidal terminology the phase describes the LT at which the wave crest crosses the Greenwich meridian. In this case it is 04:00 LT. However, the lines do not match well the morning IHFAC between 06:00 and 08:00 LT. Current peaks in the morning do not exhibit clear wave-4 patterns. Also at certain longitudes there are deviations of current features from the wave front lines. This is partly caused by the interference between wave- 3 and wave- 4 . At this stage we do not know how the DE2 and DE3 tides modulate the Sq system and why the modulations are different in the morning and afternoon. In the bottom panel, similarly, the lines represent the westward propagating terdiurnal tide with wavenumber 2 (TW2). During daylight hours positive and negative peaks in current density track the wave crests (full lines) and valleys (dashed lines) reasonably well. This indicates that tidal waves have a significant influence on the distribution and direction of IHFACs.

So far we have considered only IHFACs derived from solar maximum years. For completeness we looked also in the data from the recent deep minimum years (2005-2009). The average solar flux level amounts to about 70 sfu. In Fig. 6 the IHFAC distribution has again been plotted in an LT versus GLON frame, as in Fig. 5. When comparing the two figures we find in the upper frame a very similar IHFAC distribution: prominent northward currents around noon that shift towards earlier LTs at longitudes east of $180^{\circ} \mathrm{E}$. Also for the time period November-March we obtain similar IHFAC features from both solar-activity intervals. IHFAC density peaks line up again along the same wave fronts. Overall the plots from solar minimum years are smoother and the wave features come out clearer in Fig. 6. The current densities are comparable in spite of the big difference in solar flux level between the two periods. Note that the strength of Sq current is known to increase significantly with solar activity (e.g., Takeda, 2002). It seems that the asymmetry between northern and southern Sq vortices, which results in IHFAC, is not affected strongly by solar flux variations. The IHFAC peak associated with the SAA is slightly less prominent during solar minimum. What is the process responsible for this change? In Sect. 4.2 we mention the low B-field strength that favours larger dynamo efficiency and the precipitation from the radiation belt that enhances the electron density. In our opinion the solar cycle dependence of the latter process (e.g., Fig. 7 of Dmitriev and Yeh, 2008) is the one that causes the weakening of the Sq currents in the SAA region during solar minimum.

The origin of strong daytime TW2 tides during November-March is worth further discussion. The terdiurnal non-migrating tide has to be excited through nonlinear 
interaction of a primary tide with another wave. According to the scheme presented by Hagan and Roble (2001) TW2 can be generated when the semi-diurnal wave SW2 interacts with D0, the symmetric breathing of the atmosphere:

$\mathrm{TW} 2=\mathrm{SW} 2+\mathrm{D} 0$,

Though diurnal solar tide is a dominant driver of the Sq current system, semi-diurnal anti-symmetric tide is also an important modulator (e.g., Stening, 1989, and references therein). An interference of semi-diurnal tides with another wave may well occur and thus modulate Sq currents. The importance of D0 seems to be limited to the months NovemberMarch. From Fig. 6 we can read the three times 07:00, 15:00, and 23:00 LT for the wave phase. The role of non-migrating tides for the Sq system and IHFAC has never been studied before. In particular, the pronounced effect of the TW2 tide came as a surprise and highlights our lack of knowledge. More studies and modeling efforts are required for a better understanding of the tidal modulation of the current system.

\section{Summary}

From geomagnetic field observations of CHAMP from 2001 to 2009 we extracted magnetic signatures of interhemispheric field-aligned currents (IHFACs). Our results are in general agreement with previous observations.

1. During nighttime IHFACs are negligibly small.

2. Solstitial IHFACs flow from summer to winter (from winter to summer) at dawn (around noon), which is consistent with previous theoretical/observational works.

3. Duskside IHFACs are southbound irrespective of season. It generally agrees with previous observations, including those which are inconsistent with currentlyaccepted IHFAC concept. More thorough theoretical investigations are warranted in the future.

4. During equinoxes, when considering $\sim 1$ month delay from the true equinox epoch, the LT variation of IHFAC shows an intermediate behavior between the two solstitial patterns.

We have also found some new IHFAC properties, which have been partly predicted by theories, but were not yet observationally supported.

1. IHFACs clearly exhibit longitudinal variability. In general, noontime IHFACs to the east of $180^{\circ} \mathrm{E}$, where the magnetic equator is located to the south of the geographic equator, are directed more southward than in the other longitude sector. This is consistent with the theoretical prediction of Fukushima (1979).
2. Noontime IHFACs near the sector of the SAA have a stronger southward component compared to the surrounding regions irrespective of season. It can be explained by the enhanced dynamo efficiency around the SAA.

3. During equinoxes and June solstice noontime IHFACs show longitudinal wavenumber- 4 structures. A latitudinal asymmetry of the DE3 tide driving of the Sq system, as previously reported, can explain the wave4 signature in IHFACs. During December solstice IHFACs exhibit prominent longitudinal signatures of nonmigrating TW2 rather than DE3 tides, which implies an interaction of the semi-diurnal solar tide with the D0 wave during those months.

4. IHFACs show little dependence on the solar cycle. The LT-GLON distributions of IHFACs during 2001-2005 and 2005-2009 exhibit compatible magnitude and morphology.

Acknowledgements. The CHAMP mission is sponsored by the Space Agency of the German Aerospace Center (DLR) through funds of the Federal Ministry of Economics and Technology, following a decision of the German Federal Parliament (grant code 50EE0944). The data retrieval and operation of the CHAMP satellite by the German Space Operations Center (GSOC) is acknowledged.

Topical Editor K. Kauristie thanks S. England and A. Chulliat for their help in evaluating this paper.

\section{References}

Abdu, M. A., Batista, I. S., Carrasco, A. J., and Brum, C. G. M.: South Atlantic magnetic anomaly ionization: A review and a new focus on electrodynamic effects in the equatorial ionosphere, J. Atmos. Solar Terr. Phys., 67, 1643-1657, 2005.

Campbell, H. W.: Introduction to Geomagnetic Fields, Cambridge Univ. Press, New York, 1997.

Chapman, S. and Bartels, J.: Geomagnetism, Oxford Univ. Press, London, 1940.

Chulliat, A., Blanter, E., Le-Mouël, J.-L., and Shnirman, M.: On the seasonal asymmetry of the diurnal and semidiurnal geomagnetic variations, J. Geophys. Res., 110, A05301, doi:10.1029/2004JA010551, 2004.

Dmitriev, A. and Yeh, H.-C.: Storm-time ionization enhancements at the topside low-latitude ionosphere, Ann. Geophys., 26, 867876, doi:10.5194/angeo-26-867-2008, 2008.

England, S. L., Immel, T. J., Huba, J. D., Hagan, M. E., Maute, A., and DeMajistre, R.: Modeling of multiple effects of atmospheric tides on the ionosphere: An examination of possible coupling mechanisms responsible for the longitudinal structure of the equatorial ionosphere, J. Geophys. Res., 115, A05308, doi:10.1029/2009JA014894, 2010.

Fukushima, N.: Electric potential difference between conjugate points in middle latitudes caused by asymmetric dynamo in the ionosphere, J. Geomag. Geoelec., 31, 401-409, 1979. 
Fukushima, N.: Some Topics and Historical Episodes in Geomagnetism and Aeronomy, J. Geophys. Res., 99(A10), 1911319142, 1994.

Hagan, M. and Roble, R.: Modeling diurnal tidal variability with the National Center for Atmospheric Research thermosphere-ionosphere-mesosphere-electrodynamics general circulation model, J. Geophys. Res., 106(A11), 24869-24882, 2001.

Hagan, M. E., Maute, A., Roble, R. G., Richmond, A. D., Immel, T. J., and England, S. L.: Connections between deep tropical clouds and the Earth's ionosphere, Geophys. Res. Lett., 34, L20109, doi:10.1029/2007GL030142, 2007.

Hesse, D.: An investigation of the electrojet by means of groundbased magnetic measurements in Brazil, Ann. Geophys., 38, 315-320, 1982.

Lühr, H., Häusler, K., and Stolle, C.: Longitudinal variation of $\mathrm{F}$ region electron density and thermospheric zonal wind caused by atmospheric tides, Geophys. Res. Lett., 34, L16102, doi:10.1029/2007GL030639, 2007.

Lühr, H., Rother, M., Häusler, K., Alken, P., and Maus, S.: The influence of nonmigrating tides on the longitudinal variation of the equatorial electrojet, J. Geophys. Res., 113, A08313, doi:10.1029/2008JA013064, 2008.

Maeda, H.: Field-aligned current induced by asymmetric dynamo action in the ionosphere, J. Atmos. Terr. Phys., 36(8), 13951401, 1974.

Manoj, C., Lühr, H., Maus, S., and Nagarajan, N.: Evidence for short spatial correlation lengths of the noon-time equatorial electrojet - inferred from a comparison of satellite and ground magnetic data, J. Geophys. Res., 111, A11312, doi:10.1029/2006JA011855, 2006

Matsushita, S. and Maeda, H.: On the Geomagnetic Solar Quiet Daily Variation Field during the IGY, J. Geophys. Res., 70(11), 2535-2558, 1965.

Mayaud, P. N.: Correlation entre les variations journalieres du champ magnetique terresstre sous l'electrojet dan les regions avoisinantes, Ann. Geophys., 23, 387-406, 1967.

Oberheide, J. and Forbes, J. M.: Tidal propagation of deep tropical cloud signatures into the thermosphere from TIMED observations, Geophys. Res. Lett., 35, L04816, doi:10.1029/2007GL032397, 2008.

Oberheide, J., Forbes, J. M., Häusler, K., Wu, Q., and Bruinsma, S. L.: Tropospheric tides from 80 to $400 \mathrm{~km}$ : Propagation, interannual variability, and solar cycle effects, J. Geophys. Res., 114, D00I05, doi:10.1029/2009JD012388, 2009.

Ogbuehi, P. O., Onwumechili, C. A., and Ifedili, S. O.: The equatorial electrojet and the worldwide part of Sq currents, J. Atmos. Terr. Phys., 29, 149-160, 1967.

Okeke, F. N.: Variability of horizontal component of geomagnetic element $(\mathrm{H})$ with mean quiet-day variation, International Journal of Geomagnetism and Aeronomy, 6, GI2005, doi:10.1029/2005GI000109, 2006.

Okeke, F. N. and Onwumechili, C. A.: Preliminary analysis of geomagnetic day to day variations in equatorial zone, Am. Inst. Phys. Con. Proc., 320, 49, 1993.
Olsen, N.: Ionospheric F region currents at middle and low latitudes estimated from Magsat data, J. Geophys. Res., 102(A3), 45634576, 1997.

Onwumechili, C. A.: The Equatorial Electrojet, Gordon and Breach Science Publishers, Amsterdam, Netherlands, 159-251, 1997.

Park, J., Lühr, H., and Min, K. W.: Characteristics of F-region dynamo currents deduced from CHAMP magnetic field measurements, J. Geophys. Res., 115, A10302, doi:10.1029/2010JA015604, 2010.

Pedatella, N. M., Forbes, J. M., and Oberheide, J.: Intra-annual variability of the lowlatitude ionosphere due to nonmigrating tides, Geophys. Res. Lett., 35, L18104, doi:10.1029/2008GL035332, 2008.

Rastogi, R. G.: Sq and sfe currents at equatorial stations along the western and eastern African sectors, Earth Planets Space, 58(11), 1475-1478, 2006.

Richmond, A. D.: Ionospheric electrodynamics using magnetic apex coordinates, J. Geomag. Geoelectr., 47, 191-212, 1995.

Stening, R. J.: Longitude and seasonal variation of the Sq current system, Radio Sci., 6, 133-137, 1971.

Stening, R. J.: A calculation of ionospheric currents due to semidiurnal antisymmetric tides, J. Geophys. Res., 94, 1525-1531, 1989.

Takeda, M.: Three dimensional ionospheric currents and field aligned currents generated by asymmetrical dynamo action in the ionosphere, J. Atmos. Terr. Phys., 44(2), 187-193, 1982.

Takeda, M.: Effects of the strength of the geomagnetic main field strength on the dynamo action in the ionosphere, J. Geophys. Res., 101(A4), 7875-7880, 1996.

Takeda, M.: Features of global geomagnetic Sq field from 1980 to 1990, J. Geophys. Res., 107, 1252, doi:10.1029/2001JA009210, 2002.

Takeda, M., Iyemori, T., and Saito, A.: Relationship between electric field and currents in the ionosphere and the geomagnetic Sq field, J. Geophys. Res., 108(A5), 1183, doi:10.1029/2002JA009659, 2003.

Tarpley, J. D.: THE IONOSPHERIC WIND DYNAMO-II*, SOLAR TIDES, Planet. Space Sci., 18, 1091-1103, 1970.

Tomás, A. T., Lühr, H., and Rother, M.: Mid-latitude solar eclipses and their influence on ionospheric current systems, Ann. Geophys., 27, 4449-4461, doi:10.5194/angeo-27-4449-2009, 2009.

van Sabben, D.: North-South asymmetry of Sq, J. Atmos. Terr. Phys., 26, 1187-1195, 1964.

van Sabben, D.: Magnetospheric currents associated with the N-S asymmetry of the Sq, J. Atmos. Terr. Phys., 28, 965-981, 1966.

Yamashita, S. and Iyemori, T.: Seasonal and local time dependences of the interhemispheric field-aligned currents deduced from the Ørsted satellite and the ground geomagnetic observations, J. Geophys. Res., 107(A11), 1372, doi:10.1029/2002JA009414, 2002.

Zhang, X., Forbes, J. M., and Hagan, M. E.: Longitudinal variation of tides in the MLT region: 2. Relative effects of solar radiative and latent heating, J. Geophys. Res., 115, A06317, doi:10.1029/2009JA014898, 2010. 